\section{Commentary: Open repair is the gold standard for treatment of chronic distal aortic dissection-} For now

\author{
Nicholas T. Kouchoukos, MD
}

In this issue of the Journal, Hong and Coselli ${ }^{1}$ discuss the rationale for open repair of chronic distal aortic dissection, examine the limitations of endovascular repair for this condition, and provide an excellent description of their technique for open repair of chronic Crawford extent II dissecting thoracoabdominal aortic aneurysms, including preoperative assessment and early postoperative management. The descriptive text is greatly enhanced by several elegant and informative illustrations and photographs. The authors conclude that open repair remains the gold standard for chronic distal aortic dissection and provide justification for this conclusion.

Dr Coselli and his present and former colleagues at the Baylor University School of Medicine have played a major role in the development of open surgical repair as a method of management for aneurysms of the descending thoracic and thoracoabdominal aorta, including those resulting from aortic dissection. Following in the footsteps of Drs Michael DeBakey, Denton Cooley, and E. Stanley Crawford at Baylor, Dr Coselli has amassed an extraordinary experience with open repair of thoracoabdominal aortic aneurysms, which has evolved from simple aortic clamping to the incorporation of adjuncts, including left heart bypass, ${ }^{2}$ permissive hypothermia, drainage of cerebral spinal fluid, ${ }^{3}$ aggressive implantation of intercostal or lumbar arteries, separate perfusion of the kidneys with cold crystalloid

\footnotetext{
From the Division of Cardiovascular and Thoracic Surgery, Missouri Baptist Medical Center, BJC Healthcare, St. Louis, Mo.

Disclosures: The author reported no conflicts of interest.

The Journal policy requires editors and reviewers to disclose conflicts of interest and to decline handling or reviewing manuscripts for which they may have a conflict of interest. The editors and reviewers of this article have no conflicts of interest.

Received for publication Jan 20, 2021; revisions received Jan 20, 2021; accepted for publication Jan 25, 2021; available ahead of print Jan 30, 2021.

Address for reprints: Nicholas T. Kouchoukos, MD, Missouri Baptist Medical Center, 3023 N Ballas Rd, Suite 150D, St. Louis, MO 63131 (E-mail: ntkouch@aol.com). JTCVS Techniques 2021;10:26-7

2666-2507

Copyright (c) 2021 The Authors. Published by Elsevier Inc. on behalf of The American Association for Thoracic Surgery. This is an open access article under the CC BY-NCND license (http://creativecommons.org/licenses/by-nc-nd/4.0/).

https://doi.org/10.1016/j.xjtc.2021.01.034
}

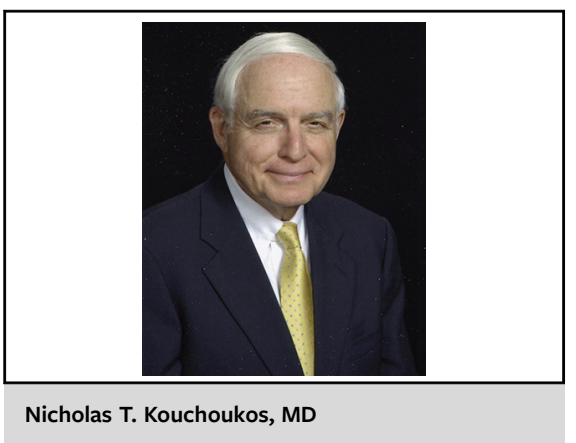

CENTRAL MESSAGE

This report is an excellent resource for any surgeon wishing to undertake repair of a Crawford extent II thoracoabdominal aortic aneurysm.

solution, isothermic blood perfusion of the celiac and superior mesenteric arteries, and use of separate grafts to the visceral and renal arteries. ${ }^{4,5}$

Despite the important modifications in technique introduced by Coselli and colleagues and by others, the major risks associated with repair of Crawford extent II aneurysms remain substantial and include early mortality, permanent spinal cord ischemic injury, renal failure, and severe pulmonary dysfunction. These risks occur with less frequency in patients with aortic dissection compared with patients with degenerative aneurysms, especially in the subgroups of patients of younger age and with heritable thoracic aortic disease. As noted by Coselli and colleagues, ${ }^{5}$ patients who survive the repair of Crawford extent II procedures but have persistent paralysis or paraparesis have markedly reduced survival compared with patients who do not develop this complication.

Hong and Coselli maintain that open repair of chronic distal aortic dissection currently represents the preferred method of management against which all other forms of treatment should be compared. However, if open repair is to maintain its status as the treatment of choice, then continued efforts to reduce early mortality and morbidity, particularly the prevalence of permanent spinal cord ischemic injury, are essential. For endovascular repair to become a suitable alternative to open repair, especially for chronic distal dissection, where the technical issues associated with endovascular repair are more formidable than for degenerative aneurysms, large multicenter trials of comparable patients treated with the 2 techniques that include 
long-term outcomes will be necessary to establish their relative safety and effectiveness.

This publication will be an invaluable resource for any surgeon wishing to undertake repair of a Crawford extent II thoracoabdominal aortic aneurysm.

\section{References}

1. Hong JC, Coselli JS. Open repair remains the gold standard. J Thorac Cardiovasc Surg Tech. 2021;10:16-23.
2. Coselli JS, LeMaire SA. Left heart bypass reduces paraplegia rates after thoracoabdominal aortic aneurysm repair. Ann Thorac Surg. 1999;67:1931-4.

3. Coselli JS, LeMaire SA, Koksoy C, Schmittling ZC, Curling PE. Cerebrospinal fluid drainage reduces paraplegia after thoracoabdominal aortic aneurysm repair: results of a randomized clinical trial. J Vasc Surg. 2002;35:631-9.

4. Coselli JS, LeMaire SA, Preventza O, de la Cruz KI, Cooley DA, Price MD, et al. Outcomes of 3309 thoracoabdominal aortic aneurysm repairs. J Thorac Cardiovasc Surg. 2016;151:1323-38.

5. Coselli JS, Green SY, Price MD, Zhang Q, Preventza O, de la Cruz KI, et al. Spinal cord deficit after 1114 extent II open thoracoabdominal aortic repairs. J Thorac Cardiovasc Surg. 2020;159:1-13. 